\title{
ROLE OF CARDIOVASCULAR MAGNETIC RESONANCE IMAGING IN ASSESSMENT OF MYOCARDIAL IRON OVERLOAD IN THALASSEMIA PATIENTS
}

\author{
Wafaa H. Abdallah (1), Ayman M. Ibrahim ${ }^{(2)}$,Hanan M. Eissa ${ }^{(2)}$, and \\ Amgad S. Abdel-Rahman ${ }^{(2)}$
}

\begin{abstract}
${ }^{1}$ Department of Radiodiagnosis; Faculty of Medicine - Ain Shams University ${ }^{2}$ Radiodiagnosis Manshyet Elbakry hospital, Ministry of Health, Cairo, Egypt.

Corresponding author:

Wafaa Hamed Mohamed Abdallah Mobile: (+2) 01067474182

E.mail:

wafaahamed83.wh@gmail.com
\end{abstract}

Received: 1/6/2021

Accepted: 29/6/2021

\section{Online ISSN: 2735-3540}

\begin{abstract}
:
Background: Thalassemia major anemia patients require repeated blood transfusions, which improves their survival and quality of life, however it leads to iron overload and cellular damage. Serum ferritin and liver biopsy were used classically to measure iron overload and to monitor patient response to chelation therapy. Magnetic resonance imaging (MRI T2*) has proven to be a noninvasive, effective technique in detecting and quantifying myocardial and hepatic iron overload and in adjustment of iron chelation therapy.
\end{abstract}

Aim of Work: To assess myocardial siderosis among our patients using MRI T2* technique and to correlate it with hepatic iron load and left ventricular ejection fraction (LVEF).

Patients and methods: Our study included 42 cases of regularly transfused patients. Hepatic and myocardial iron overload were measured by multi-breath-hold MRI T2* technique and a cine view sequence was used to assess left ventricular function $(E F)$.

Results: Myocardial and hepatic iron overload were intercorrelated to each other and correlated to left ventricular function $(L V E F)$. There was insignificant correlation between cardiac and hepatic $T 2 *$ value results $(k=0.014, P>0.05)$. However, there was a progressive and significant decline in left ventricular ejection fraction $(r=0.61, P<0.001)$ in patients with low cardiac $T 2 *$ values $(T 2 *<$ $20 \mathrm{~ms})$.

Conclusion: MRI T2* technique is a precise, reproducible, and non-invasive technique for measuring tissue iron concentration and sparing the patients from an invasive biopsy technique. It also benefits in early detection of cardiac dysfunction and provides a follow up tool helping in chelation therapy adjustment.

Key words: Cardiac MRI, Iron overload, Liver iron concentration, $T 2 *$, Thalassemia.

\section{INTRODUCTION:}

Frequent blood transfusion is considered to be the basic treatment for patients with thalassemia major. Despite regular transfusion has lifesaving benefits, it can cause further complications, particularly iron overload and hemochromatosis ${ }^{(1)}$. Iron accumulation in heart can result in cardiac dysfunction, cardiomyopathy and heart failure, which is the most common cause of deaths in these patients ${ }^{(2)}$. The liver is also susceptible to early iron deposition and liver iron overload, if not diagnosed and properly treated, rapidly develops into cirrhosis. In order to prevent hemosiderosis, iron has to be chelated and excreted ${ }^{(3)}$. 
Until recently, liver biopsy was considered the gold standard diagnostic tool to detect iron overload. However, it is invasive and resulting in several complications $^{(4)}$. Serum ferritin was used as a marker for iron load as well, but it is not specific as its level can be elevated in inflammations such as hepatitis, infections and in liver damage ${ }^{(5)}$.

The limitations of serum ferritin and liver biopsy for estimating organ iron overload make the search for non-invasive methods, with high accuracy, is necessary for assessing organs iron content ${ }^{(6)}$. The highly sensitive magnetic resonance imaging (MRI) T2* technique revolutionized thalassemia management, providing a direct assessment of cardiac and hepatic iron content and evaluating the effectiveness of iron chelation therapy $^{(7 \& 8)}$. This method allowed for early diagnosis of liver and heart hemosiderosis and a reduction in morbidity and mortality in thalassemia patients ${ }^{(9)}$. Patients with T2* values of $>20 \mathrm{~ms}$ are regarded as having no cardiac iron load, those with $\mathrm{T} 2 *$ values between 10 and $20 \mathrm{~ms}$ have mild to moderate cardiac iron load, and those with $\mathrm{T} 2 *$ values of $<10 \mathrm{~ms}$ are considered to have heavy cardiac iron load ${ }^{(10)}$.

\section{THE AIM OF WORK:}

The aim of this study was to evaluate the utility of MRI T2* technique in assessment of myocardial iron load and to correlate it with hepatic iron load and left ventricular ejection fraction (LVEF).

\section{PATIENTS AND METHODS}

The study was approved by the research ethical committee at the faculty of medicine, Ain shams university. The study was performed on 42 thalassemia major patients (18 males and 24 females, mean age 27.9 years), in radiology department, Ain shams university hospitals, Cairo, Egypt, From January 2018 till June 2019.

\section{Inclusion criteria:}

- Diagnosis of $\beta$-thalassemia major based on clinical and hematological evaluation.

- No age or sex predilection

- All patients received repeated blood transfusions (15 $\mathrm{ml}$ packed $\mathrm{RBCs} / \mathrm{kg}$ body weight every 4-8 week to keep their hemoglobin level at a level of 9-10 $\mathrm{g} / \mathrm{dl}$ before each transfusion).

\section{Exclusion criteria:}

- Patients with bad general condition.

- Patients younger than 5 years old as they did not receive enough transfusion to develop hepatic or myocardial siderosis.

- Patients known to have contraindications for MRI e.g. Cardiac pacemakers, metallic valves, hearing aids, and aneurismal clips.

\section{Patient preparation:}

All patients subjected to full clinical history, patients were asked to lie in supine position on MRI table and informed to remain motionless during the exam with regular quiet respiration and avoid excessive swallowing. The ECG electrodes were placed after cleaning the skin. Then, specific cardiac or torso coils were used for imaging with multi-element phased-array coils (16 channels), required for parallel imaging.

CMR protocol: MRI study was performed on a 1.5-T MR scanner (Philips Medical Systems, Acheiva, Netherlands), ECG and respiratory gated with dedicated phased array cardiac coil using single breath-hold multi-echo technique including:

- Single shot dual inversion black blood breath-hold scan (BB-SSh-BH); axial.

- Left Anterior Oblique (LAO) vertical long axis. 4 chamber view $(\mathrm{P} 4 \mathrm{CH})$; axial. 
- Multiecho Turbo Field Echo (mTFE) Cardiac BB (Black blood) short axis with TE (from 1.2-17.3 msec.).

- Multiecho Turbo Field Echo (mTFE) Cardiac WB (white blood) short axis with TE (from 2.3- $19.8 \mathrm{msec}$.).

- Multiecho Turbo Field Echo (mTFE) Liver FIG (Axial) with TE (from 1-12 msec.).

- After the acquisition of transverse localizer images, a two-chamber (Vertical Long-Axis (VLA)) cine image was derived by positioning a parasagittal section through the Left Ventricular (LV) apex and the middle of the mitral annulus at end expiratory phase. One slice was taken.

\section{MRI image acquisition:}

The scan was operated at a maximum gradient strength of $45 \mathrm{mT} \mathrm{m}-1$ and slow rate of $200 \mathrm{~T} \mathrm{~m}-1 \mathrm{~s}-1$. Each scan (duration, 20-30 min) included the measurement of hepatic (right lobe) and myocardial (midseptum) $2^{*}$ values and assessment of left ventricular function.

- For measuring myocardial T2* value, a single short-axis midventricular slice was acquired using a single breath-hold ECG-gated multi-echo technique (TR: 710 ms, slice thickness: $10 \mathrm{~mm}$, flip angle: $20^{\circ}$, FOV: $400 \times 300 \mathrm{~mm}$, matrix: $256 \times 96 \mathrm{~mm}$, bandwidth: $810 \mathrm{~Hz} / \mathrm{Px}$ ). This T2* sequence generated a series of eight images with TEs of $1.2-17.3 \mathrm{~ms}$ and spacing of $1.7 \mathrm{~ms}$, then region of interest (ROI) was drawn within the interventricular septum in each image to measure signal intensity.

- Ejection fraction (EF) was measured using standard CMR sequence, and cardiac dysfunction was considered at EF $<56 \%$.

- For hepatic T2* value measurement, a single transverse slice was acquired using a single breath-hold $\mathrm{T} 2 *$ pulse sequence, (ECG)-gated multi-echo technique (repetition time (TR): $200 \mathrm{~ms}$, slice thickness: $10 \mathrm{~mm}$, flip angle: $20^{\circ}$, field of view (FOV): $400 \times 238 \mathrm{~mm}$, matrix: $128 \times$ $76 \mathrm{~mm}$, bandwidth: $1955 \mathrm{~Hz} / \mathrm{Px})$. A series of 12 images was generated with echo times (TEs) of 1-12 ms and echo spacing of 1.4 $\mathrm{ms}$, then ROI was drawn in the periphery of the right hepatic lobe to measure the mean signal intensity.

\section{Image interpretation:}

- Myocardial and hepatic T2* decay was calculated using manual analysis in an electronic spread sheet by a semi-automated analysis software using Thalassemia tools (a plug in of CMR tools, Cardiovascular Imaging Solutions, London, UK).

- To derive $\mathrm{T} 2 *$, a mono-exponential trend-line was fitted with an equation in the form $\mathrm{y}=\mathrm{Ke} \mathrm{TE} / \mathrm{T} 2 *$ where $\mathrm{K}$ represents a constant, TE represents the echo time and y represents the image signal intensity.

- For $\mathrm{T}^{*}$ analysis, the mean signal intensity of each image was plotted against TE for each image. The T2*value was then calculated from the resulting exponential decay curve.

- Analysis of heart and liver T2* generally was completed within 2 min. In heavily-iron loaded tissues, signal decay occurred rapidly with noise dominating the signal at later echo times, to minimize it truncation was done according to ${ }^{(11)}$.

- Myocardial iron concentration (MIC) and liver iron concentration (LIC) were calculated using the calibrated technique.

According to cardiac and hepatic T2* values, iron overload risk stratification in patients was as follow:

\section{A- For cardiac T2* values, cutoff points were:}

Normal level:

$>20 \mathrm{~ms}$.

Low risk:

$15-20 \mathrm{~ms}$.

Intermediate risk:

$10-15 \mathrm{~ms}$.

High risk:

$<10 \mathrm{~ms}$. 
Functional assessment of the heart on workstation was added to measure Ejection Fraction (EF), End Systolic Volume (ESV), and End Diastolic Volume (EDV).

\section{B- For hepatic T2* values, cutoff points were: \\ Normal level: $\quad>11.4 \mathrm{~ms}$. \\ Low risk: \\ Intermediate risk: \\ 3.8- $11.4 \mathrm{~ms}$. \\ High risk: \\ $1.8-3.8 \mathrm{~ms}$.}

\section{Statistical analysis:}

The collected data were revised, coded, tabulated and introduced to a PC using Statistical Package for the Social Science (IBM Corp. Released 2011. IBM SPSS Statistics for Windows, Version 20.0. Armonk, NY: IBM Corp). Data were presented and suitable analysis was done according to the type of data obtained for each parameter.

\section{RESULTS:}

Our study was performed on 42 thalassemia major patients (18 males and 24 females, mean age 27.9 years). Out of the studied patients, 24 patients $(57.1 \%)$ had normal iron load in myocardium while five patients $(11.95 \%)$ had severe iron overload. Mild and moderate iron overload were presented in 8 patients $(19 \%)$ and 5 (11.95\%) patients, respectively.

Majority of studied patients; 25 (59.5\%) had severe iron overload in liver while 7 patients $(16.7 \%)$ and 10 patients $(23.8 \%)$ had mild and moderate hepatic iron deposition, respectively, none of the patients had normal liver.

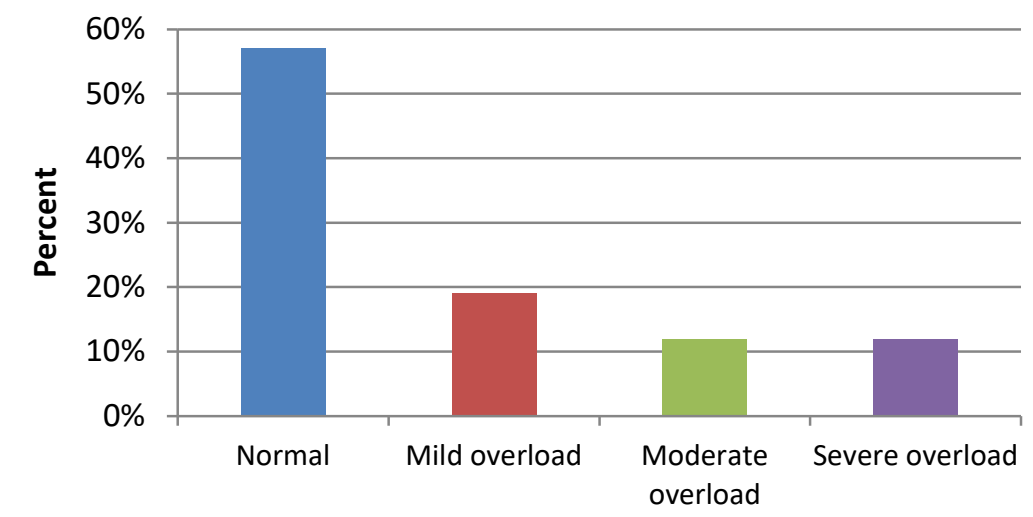

Diagram (1): A chart showing cardiac T2* intensity among patients, with more than half of cases had normal cardiac $\mathrm{T} 2 *$ value.

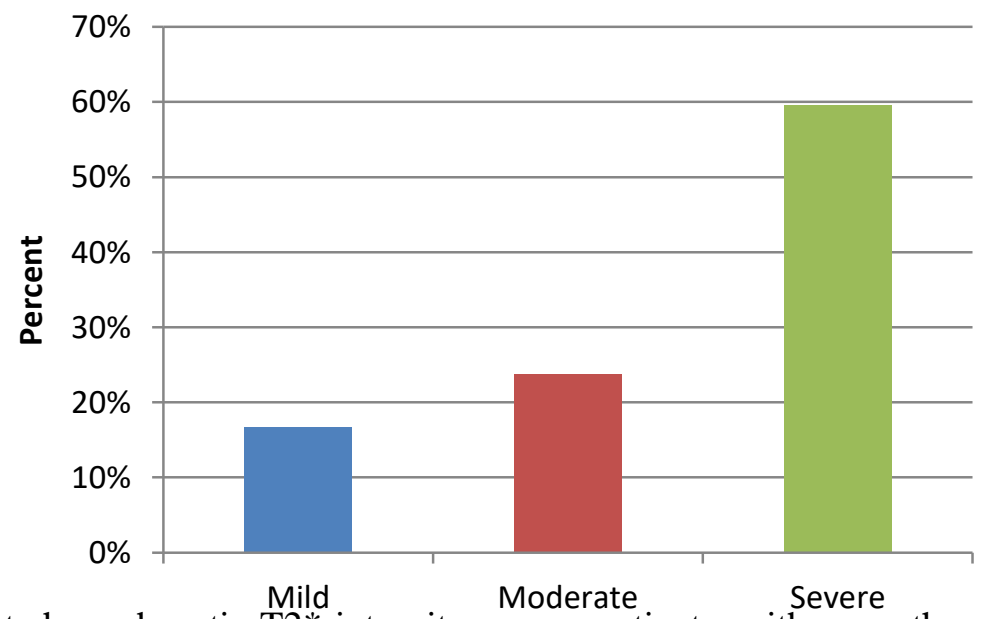

Diagram (2): A chart shows hepatic $\mathrm{T}^{*}$ intensity among patients, with more than half of cases had low hepatic $\mathrm{T} 2 *$ value denoting severe iron overload. 
The study shows a slight nonsignificant agreement between cardiac and hepatic iron overload $(\mathrm{k}=0.014, \mathrm{p}>0.05)$, as $41.7 \%$ of patients with normal cardiac $\mathrm{T} 2 *$ values had severe hepatic iron load, $75 \%$ of patients with mild cardiac $\mathrm{T} 2 *$ cases had severe hepatic iron overload, and $80 \%$ of patients with moderate cardiac T2 cases had severe hepatic iron overload (Table 1).

Table (1): The table shows liver iron concentration correlating poorly with myocardial iron concentration. NS*means no significant correlation.

\begin{tabular}{|c|c|c|c|c|c|c|c|c|c|c|c|}
\hline & \multicolumn{8}{|c|}{ Cardiac T2* value } & \multirow{3}{*}{$\begin{array}{c}P \\
\text { value }\end{array}$} & \multirow[t]{3}{*}{ Significance } \\
\hline & & \multicolumn{2}{|c|}{ Normal } & \multicolumn{2}{|c|}{ Mild } & \multicolumn{2}{|c|}{ Moderate } & \multicolumn{2}{|c|}{ Severe } & & \\
\hline & & $\mathrm{N}$ & $\%$ & $\mathrm{~N}$ & $\%$ & $\mathrm{~N}$ & $\%$ & $\mathrm{~N}$ & $\%$ & & \\
\hline \multirow{4}{*}{$\begin{array}{l}\text { Hepatic T2* } \\
\text { value }\end{array}$} & Normal & 0 & $0 \%$ & 0 & $0 \%$ & 0 & $0 \%$ & 0 & $0 \%$ & \multirow[t]{4}{*}{0.78} & \multirow[t]{4}{*}{ NS* } \\
\hline & Mild & 7 & $29.2 \%$ & 0 & $0 \%$ & 0 & $0 \%$ & 0 & $0 \%$ & & \\
\hline & Moderate & 7 & $29.2 \%$ & 2 & $25.0 \%$ & 1 & $20.0 \%$ & 0 & $0 \%$ & & \\
\hline & Severe & 10 & $41.7 \%$ & 6 & $75.0 \%$ & 4 & $80.0 \%$ & 5 & $100.0 \%$ & & \\
\hline
\end{tabular}

$* P$ value indicates the level of correlation significance between two variables.

In the normal range of myocardial $\mathrm{T} 2 *$ (cardiac $\mathrm{T} 2 *>20 \mathrm{~ms}$ ), parameters of ventricular function (ejection fraction, ESV, EDV) fell within the normal range. Below a myocardial $\mathrm{T}_{2} *$ of $20 \mathrm{~ms}$, there was a progressive and significant decline in left ventricular ejection fraction $(\mathrm{r}=0.61, P<$ $0.001)$ and an increase in the left ventricular end-systolic volume $(\mathrm{r}=0.50, P<0.002)$ as shown in (Table 2) that correlate between cardiac $\mathrm{T}^{*}$ and functional assessment of the heart.

Table (2): There was a significant positive correlation between cardiac iron load and LVEF with significant decline in LVEF in cardiac T2* value $<20 \mathrm{~ms}$. HS* means high significance and NS*means no significant correlation.

\begin{tabular}{|c|c|c|c|c|c|c|c|c|c|c|}
\hline & \multicolumn{8}{|c|}{ Cardiac T2* value } & \multirow{3}{*}{$\mathrm{P}$ value } & \multirow{3}{*}{ Significance } \\
\hline & \multicolumn{2}{|c|}{ Normal } & \multicolumn{2}{|c|}{ Mild } & \multicolumn{2}{|c|}{ Moderate } & \multicolumn{2}{|c|}{ Severe } & & \\
\hline & Mean & \pm SD & Mean & $\pm \mathrm{SD}$ & Mean & $\pm \mathrm{SD}$ & Mean & \pm SD & & \\
\hline LVEF\% & 66.71 & 5.86 & 52.00 & 1.85 & 46.20 & 2.28 & 40.80 & 2.39 & 0.001 & $\mathrm{Hs}^{*}$ \\
\hline EDV ml & 101.17 & 31.57 & 83.75 & 24.22 & 77.38 & 21.89 & 110.68 & 47.44 & 0.21 & NS* \\
\hline ESV ml & 34.05 & 13.98 & 39.70 & 10.84 & 36.42 & 6.63 & 65.90 & 30.87 & 0.002 & HS \\
\hline
\end{tabular}

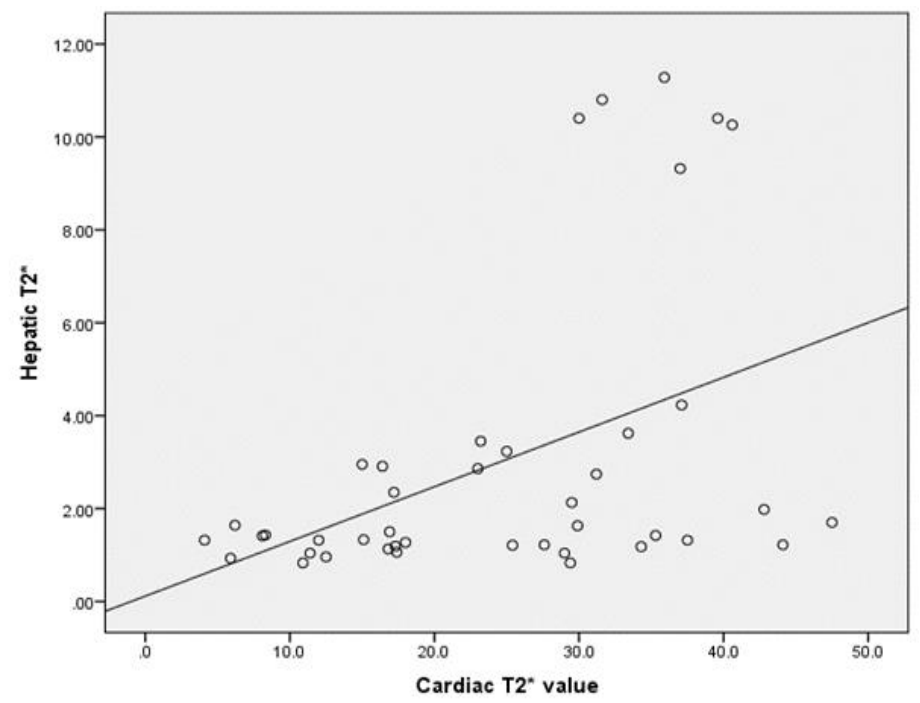

Diagram (3): Relationship between hepatic and cardiac T2*values 


\section{Case (1):}

25 years old female patient known to be thalassemic on regular blood transfusion every 8 weeks. Left ventricle functional assessment showed normal EF about $57 \%$.

(a)

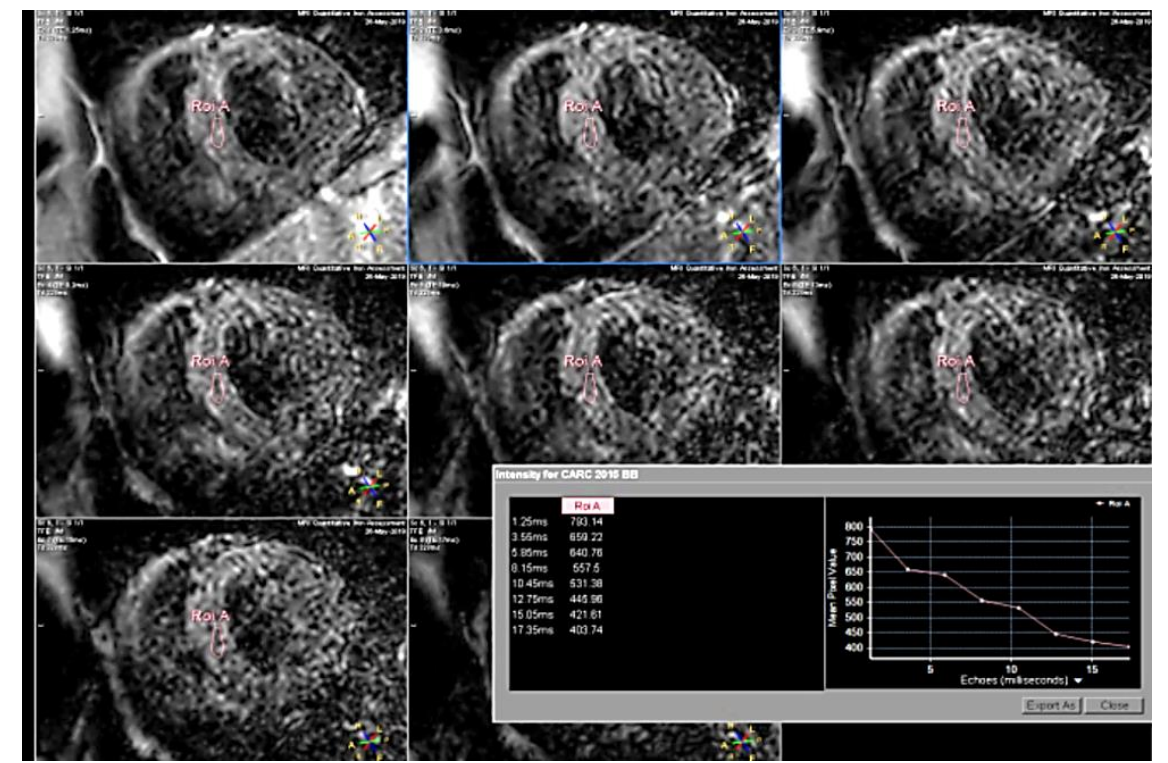

(b)

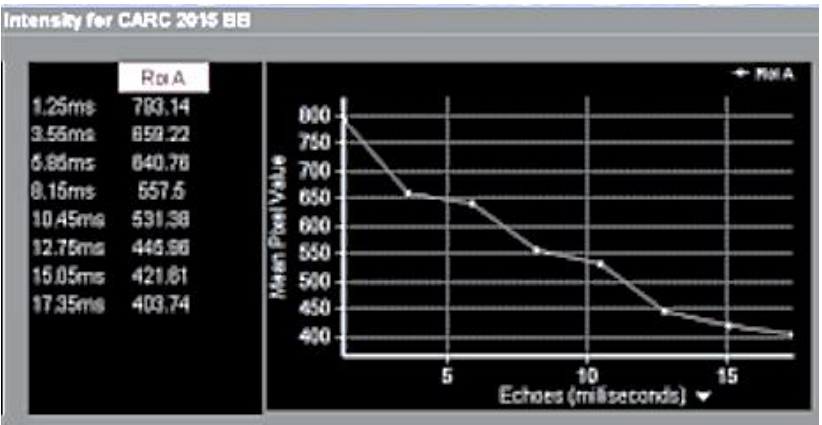

Figure ( $1 \mathrm{a} \& \mathrm{~b}$ ): (a) cMRI T2* left ventricular (LV) short axis with ROI drawn at mid IVS, (b) T2* relaxation curve plotting signal intensity against echo times showing no significant signal decay denoting no iron deposition.

(a)

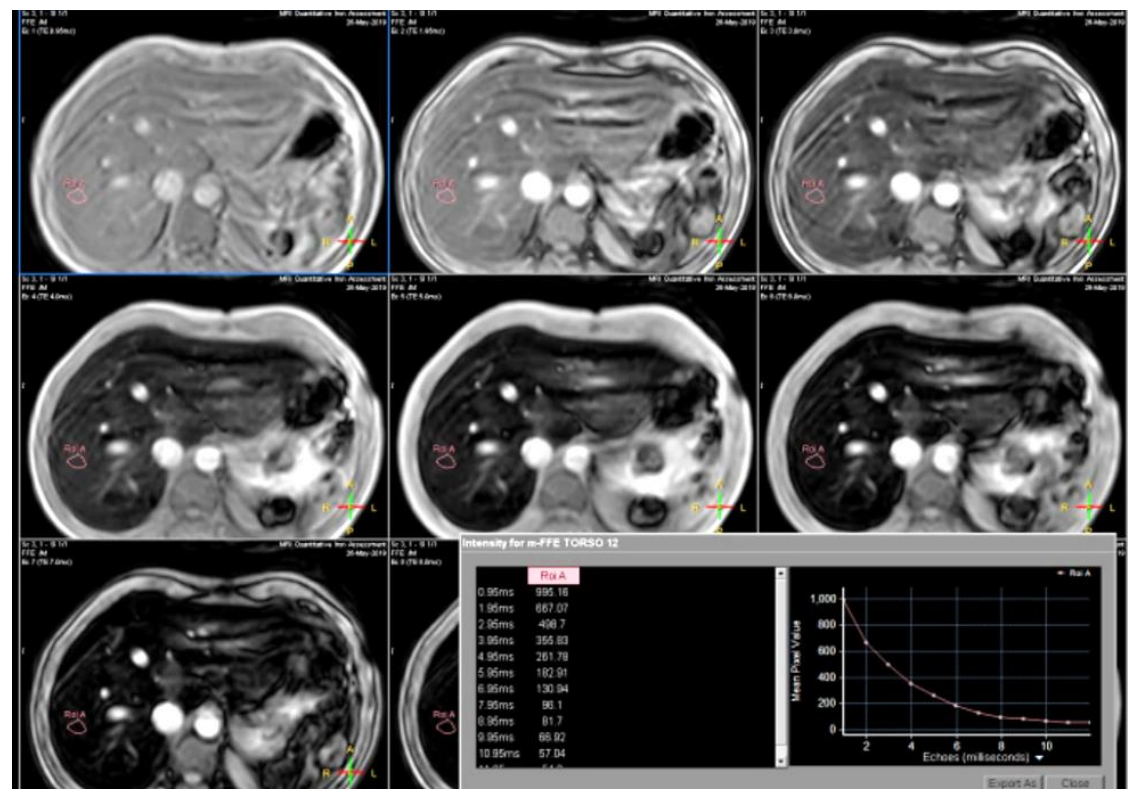


Role Of Cardiovascular Magnetic Resonance Imaging In Assessment Of Myocardial Iron Overload..

(b)

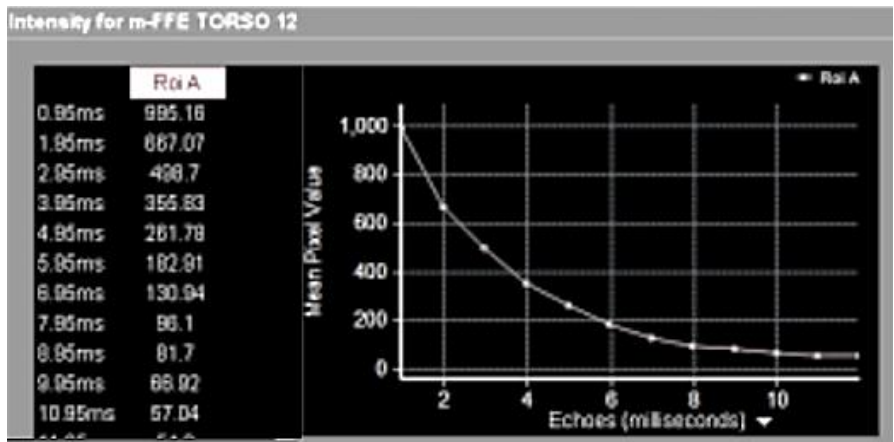

Figure (2 a\&b): (a) MRI assessment of hepatic T2* value with a ROI drawn in the periphery of the right hepatic lobe (highlighted in red), (b) shows slow signal decay over time indicating moderate hepatic iron load.

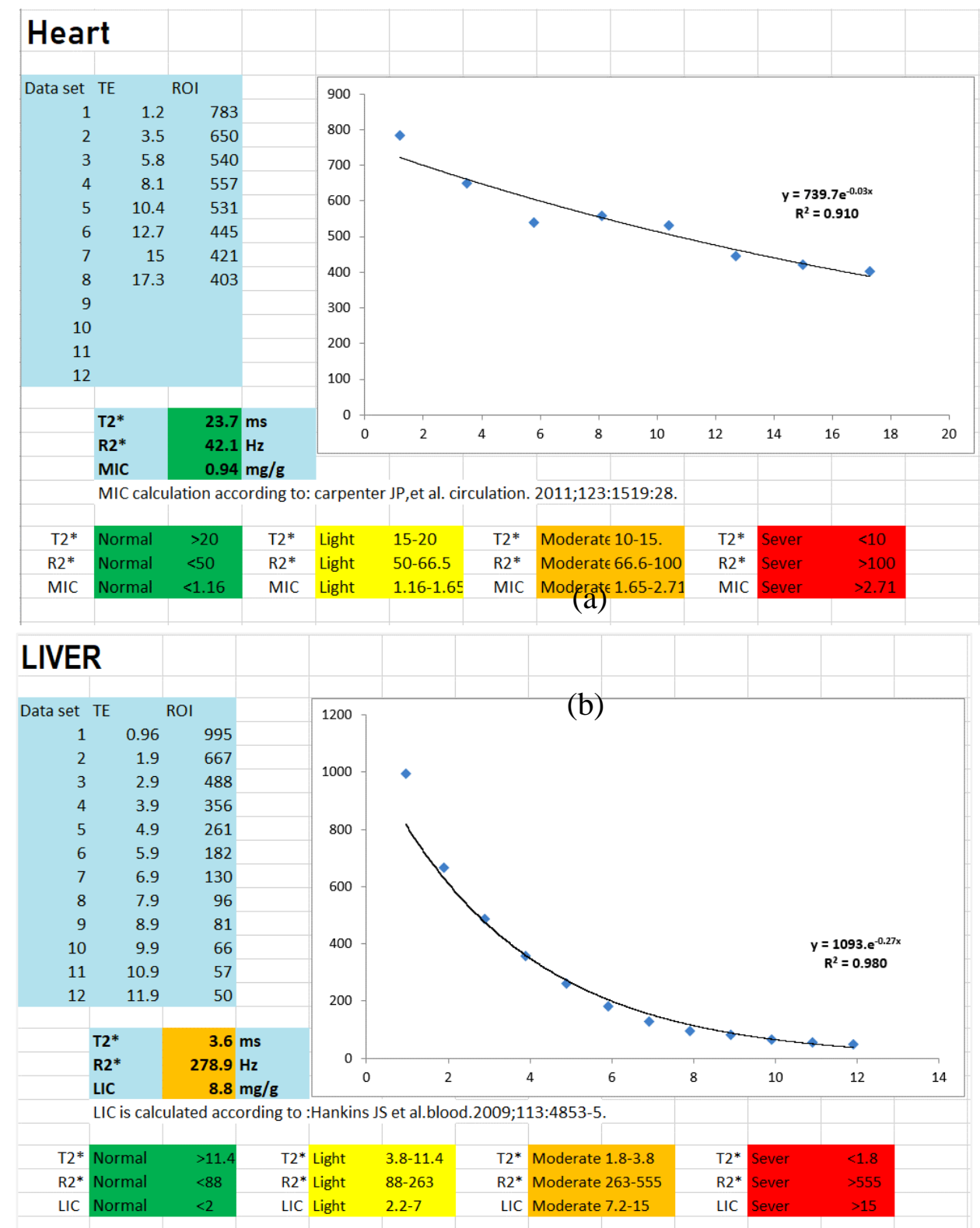

Diagram (4 a\&b): Data analysis using thalassemia tools (CMR tools, Cardiovascular Imaging Solutions, London, UK), (a) shows normal myocardial T2* (cardiac T2* value $=23.7 \mathrm{~ms}$ ' normal $>20$ ms'), (b) shows moderate hepatic T2* (hepatic T2* value $=3.6 \mathrm{~ms}$ 'moderate between $1.8-3.8 \mathrm{~ms}$ '). 


\section{Case (2):}

52 years old male patient known to be thalassemic on regular blood transfusion every 6weeks. Functional assessment revealed decreased $\mathrm{EF}=46 \%$. Accordingly, iron chelation treatment was adjusted.

(a)

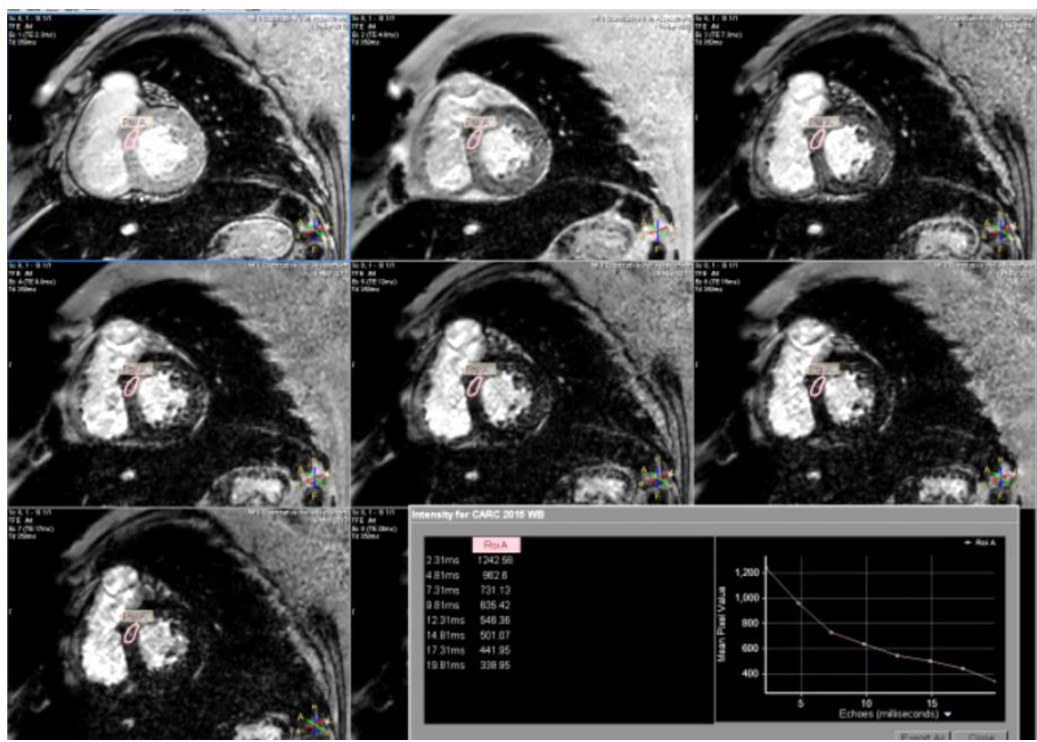

(b)

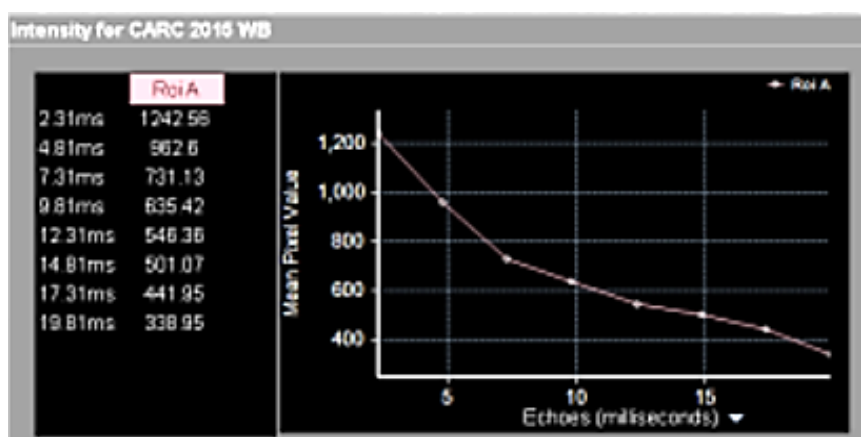

Figure ( $3 \mathrm{a} \& b$ ): (a) cMRI T2* LV short axis ROI drawn on IVS, in (b) T2* relaxation curve showing slow signal decay overtime denoting moderate iron deposition.

(a)

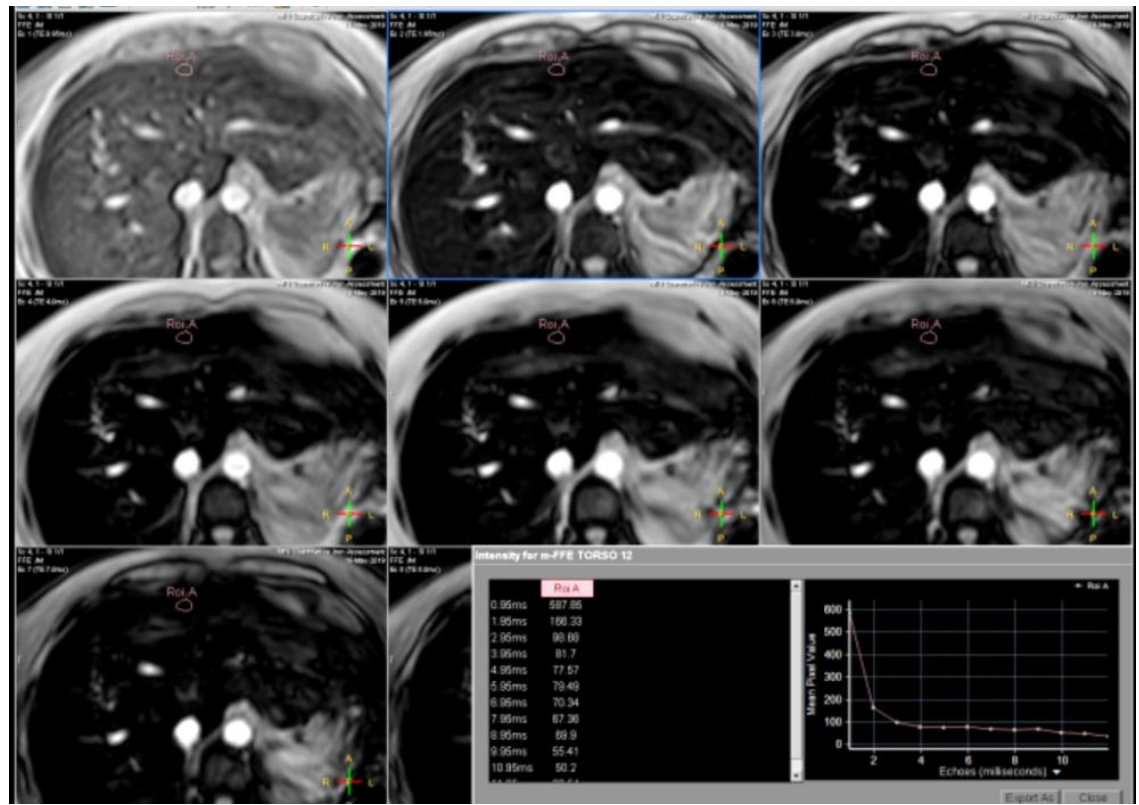


Role Of Cardiovascular Magnetic Resonance Imaging In Assessment Of Myocardial Iron Overload..

(b)

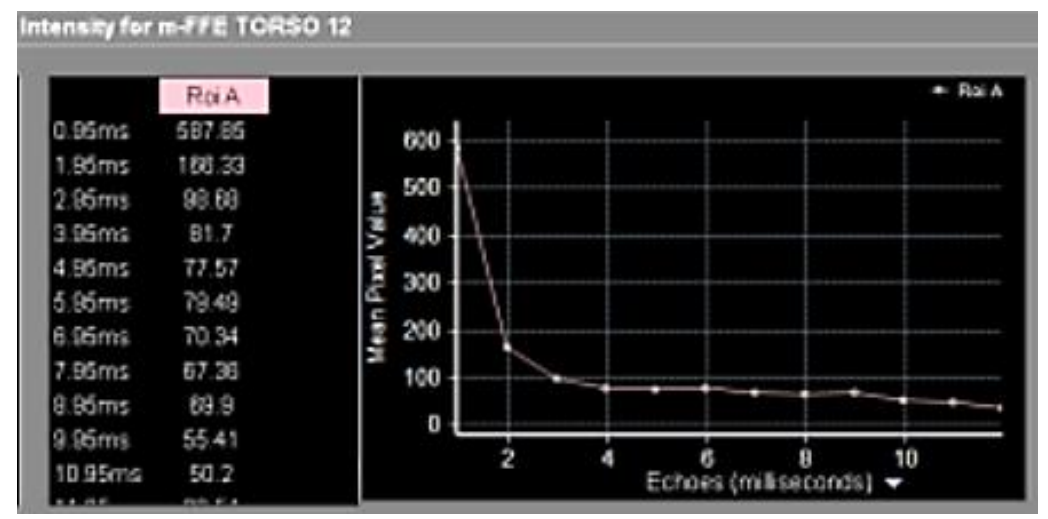

Figure ( $4 \mathrm{a} \& b$ ): MRI assessment of hepatic T2* value showing fast signal decay over time indicating sever hepatic iron load.

(a)

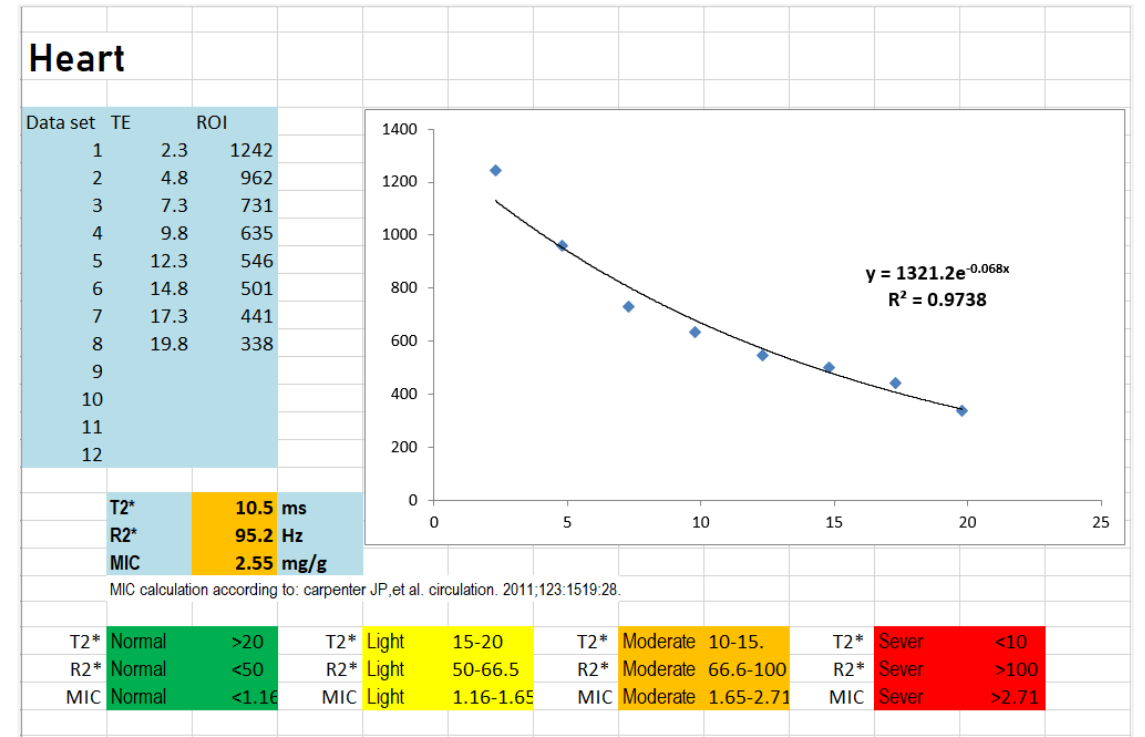

(b)

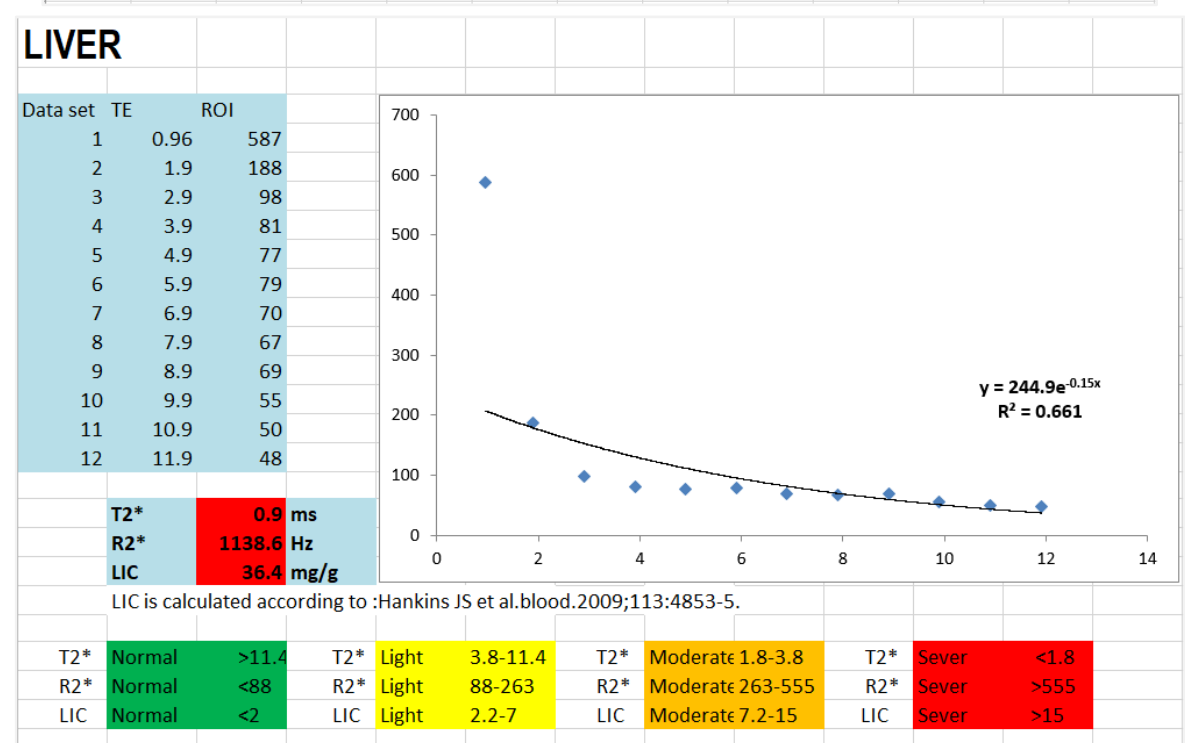

Diagram ( $5 \mathrm{a} \& \mathrm{~b})$ : Data analysis using thalassemia tools showing moderate myocardial $\mathrm{T} 2 *$ in (a) and low hepatic $\mathrm{T} 2 *$ values in $(\mathrm{b})$ (cardiac T2* value $=10.5 \mathrm{~ms}$, and hepatic $\mathrm{T} 2 *$ value $=0.9 \mathrm{~ms}$ ). 
Case (3):

30 years old female patient known to be thalassemic on regular blood transfusion every 6 weeks, with splenectomy.
Functional assessment revealed low $\mathrm{EF}=$ $45 \%$. Accordingly, iron chelation treatment adjustment was done to prevent end organ damage and prolong survival.

(a)

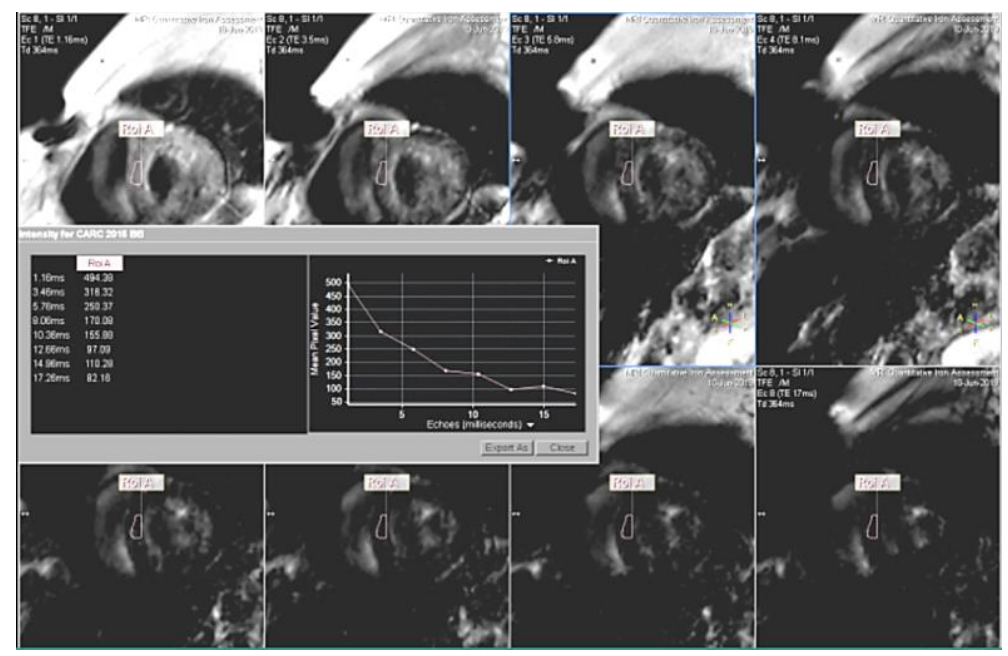

(b)

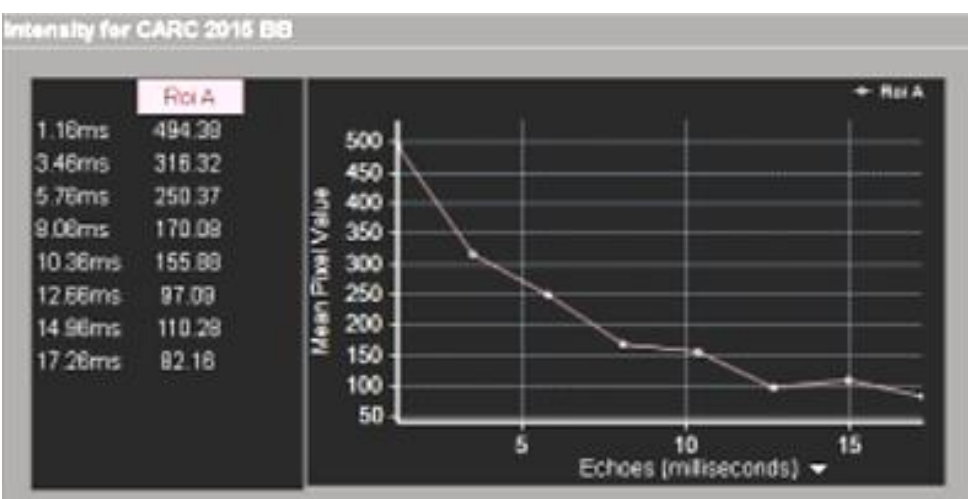

Figure ( $5 \mathrm{a} \& \mathrm{~b})$ : cMRI T2* LV short axis with T2* relaxation curve showing significant signal decay denoting sever iron deposition.

(a)

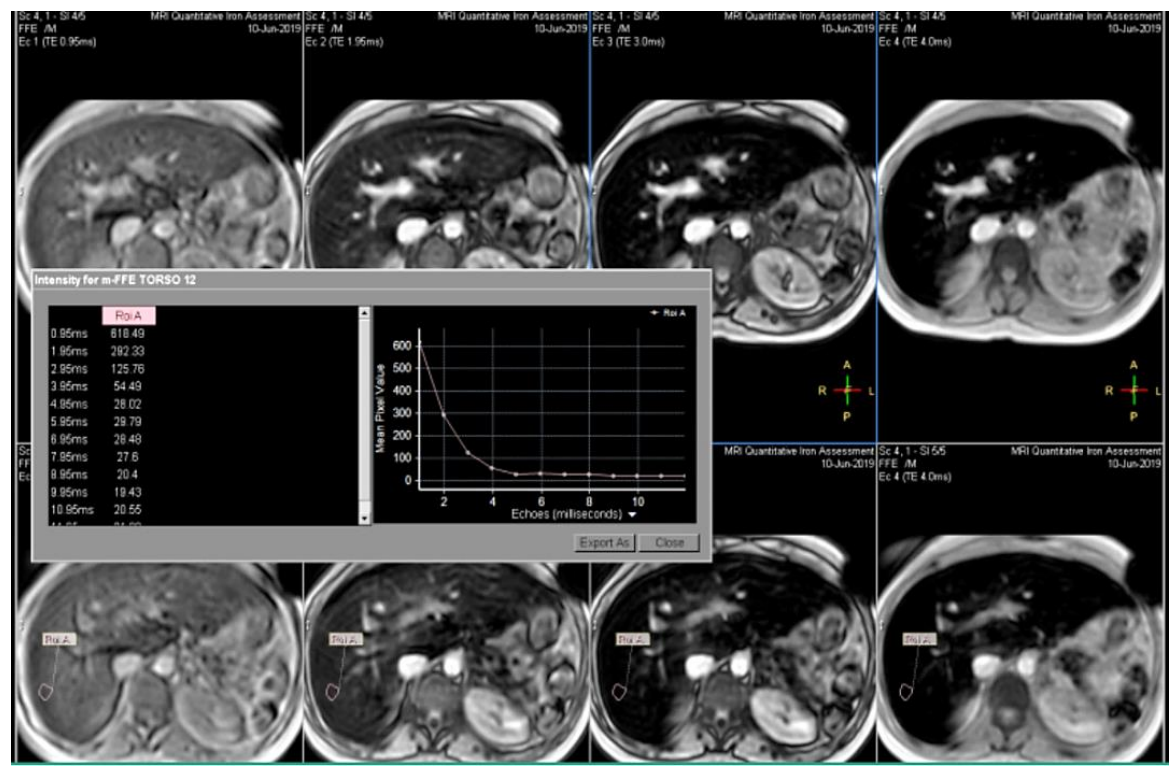


Role Of Cardiovascular Magnetic Resonance Imaging In Assessment Of Myocardial Iron Overload..

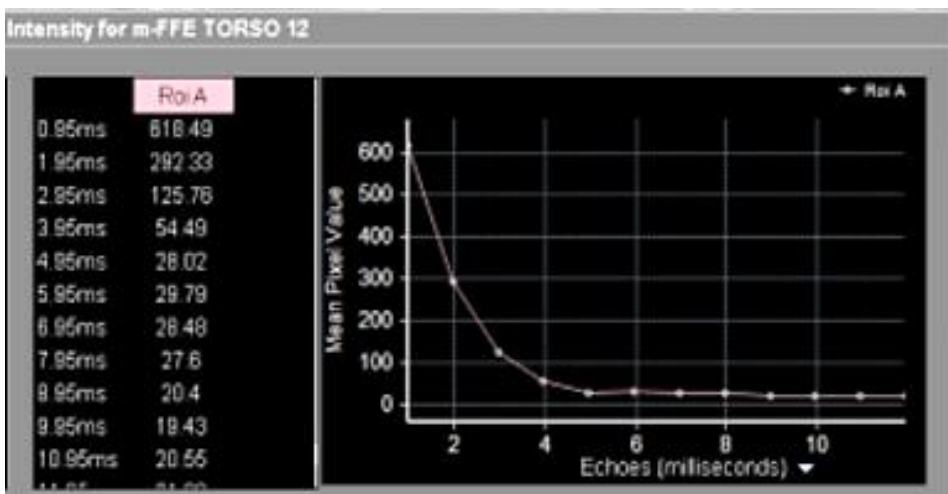

Figure ( $6 \mathrm{a} \& \mathrm{~b})$ : MRI assessment of hepatic $\mathrm{T} 2 *$ value showing fast signal decay over time indicating sever hepatic iron load.

(a)

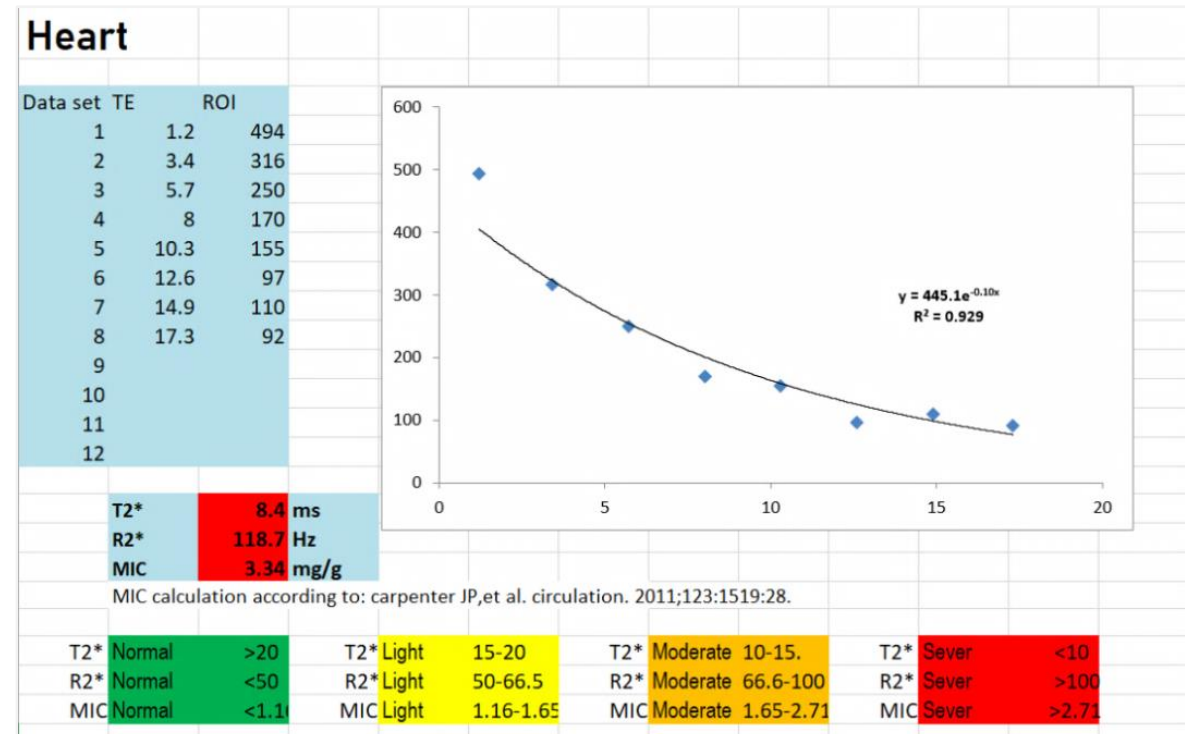

(b)

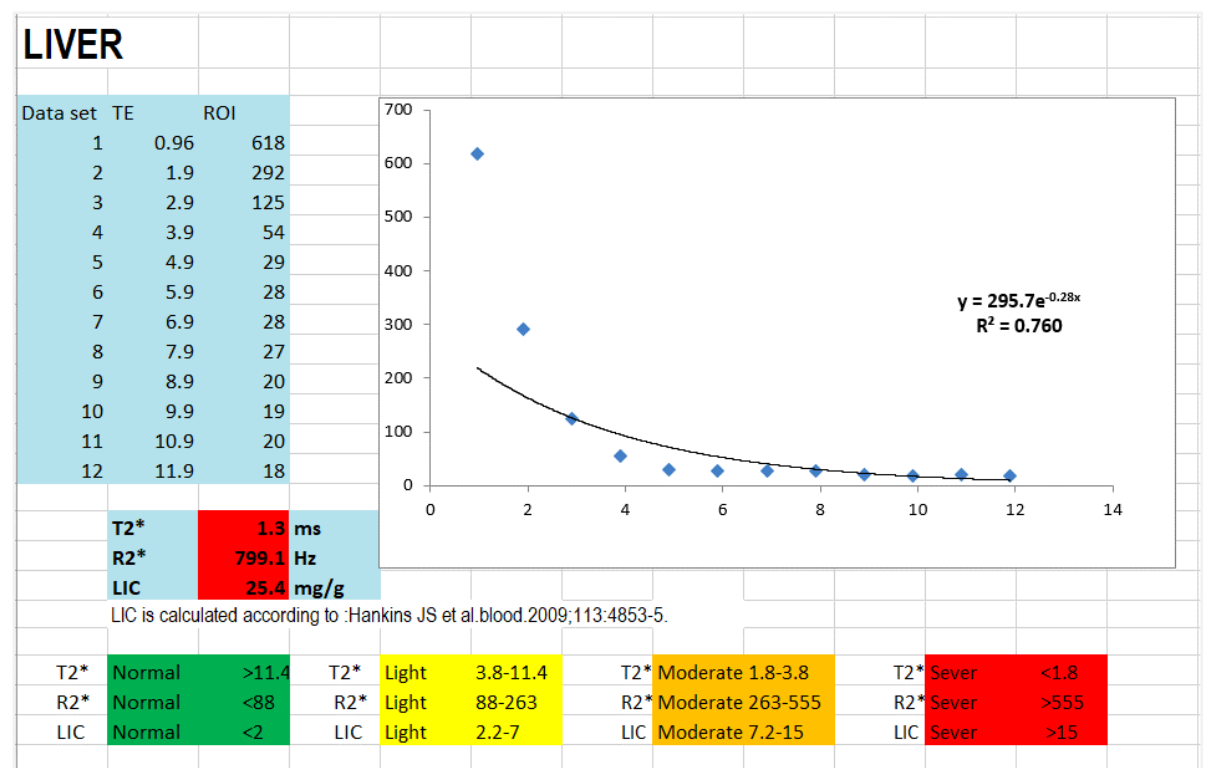

Diagram (6 a\&b): Data analysis using thalassemia tools showing low myocardial and hepatic T2* values $($ cardiac $\mathrm{T} 2 *$ value $=8.4 \mathrm{~ms}$, and hepatic $\mathrm{T} 2 *$ value $=1.3 \mathrm{~ms}$ ) denoting sever cardiac and hepatic iron overload. 


\section{DISCUSSION:}

Repeated blood transfusion results in increased myocardial iron deposition which can cause a progressive cardiomyopathy, resulting in cardiovascular complications that remain the main cause of deaths in patients with thalassemia major ${ }^{(\mathbf{1 2})}$. Therefore, myocardial iron measurement is important to assess the prevalence of myocardial siderosis among those patients ${ }^{(13)}$.

Liver iron concentration quantitated by biopsy, and measurement of serum ferritin levels have been the only methods available to assess iron overload ${ }^{(\mathbf{1 4})}$. But biopsy is an invasive method and iron deposition tends to be patchy providing, sometimes, false negative reports ${ }^{(\mathbf{1 5})}$ and serum ferritin level could be elevated by other diseases providing, sometimes, false negative reports. Therefore, it is not surprising that alternative, noninvasive, but accurate methods for the assessment of iron deposition have been sought in recent years $^{(\mathbf{1 4})}$.

A cardiac MRI T2* technique developed by Pennell and Anderson's team at the Royal Brompton Hospital in London was available that makes use of $\mathrm{T} 2 *$ to achieve a non-invasive method for quantifying myocardial iron overload ${ }^{(\mathbf{1 6})}$ and it represents a major step forward in adjusting chelation therapy and management of post-transfusion iron overload ${ }^{(17)}$.

Out of the studied patients, 24 patients (57.1\%) had normal cardiac $\mathrm{T} 2 *$ value, while 5 patients $(11.95 \%)$ had severe iron overload. Mild and moderate iron overload were presented in 8 patients $(19 \%)$ and 5 patients $(11.95 \%)$, respectively. On the other hand, majority of studied patients; 25 patients $(59.5 \%)$ had severe hepatic iron overload while 7 patients $(16.7 \%)$ and 10 patients $(23.8 \%)$ had mild and moderate hepatic iron deposition, respectively, none of these included cases in the study had normal liver.

This agrees with a study by Wahidiyat et $\boldsymbol{a l}^{(\mathbf{1 8})}$ in Indonesia that showed the majority of the patients had acceptable cardiac iron and all of them had liver iron overload. Cardiac and liver iron load showed no relationship with age. Similar result was found in Merchant et $\boldsymbol{a l}^{(\mathbf{( 1 9 )}}$ study that demonstrated liver siderosis in $90 \%$ of thalassemia major patients; however, they observed severe overload in 53\%. This is a high frequency of severe liver siderosis and may be due patient noncompliance to chelation therapy.

In our study, liver iron concentration was poorly correlated with myocardial iron concentration. There was no statistically significant difference in the liver iron $\mathrm{T} 2 *$ levels between those with or without detectable cardiac siderosis $(\mathrm{k}=0.014, \mathrm{p}>$ 0.05 ), as $41.4 \%$ of patients with normal cardiac T2* values had severe hepatic iron overload, $75 \%$ of patients with mild cardiac siderosis had severe hepatic iron overload, and $80 \%$ of patients with moderate cardiac siderosis had severe hepatic iron load.

This is in agreement with observational data from a study by Deborah et al. $^{(20)}$ which found a poor correlation between liver and cardiac iron load assessed by MRI-T2* in patients with transfusion dependent anemia. And with Wahidiyat et al. ${ }^{(18)}$ study that showed the magnitude of liver iron overload does not correlate with myocardial iron. In other studies, like Merchant et al. (19) and Farhangi et al. ${ }^{(21)}$ studies no correlation was found between liver and heart iron load.

Left ventricular function was measured using standard specific CMR sequence (EF, EDV, and ESV) and an ejection fraction (EF) $<56 \%$ was considered as cardiac dysfunction. A strong correlation was found between myocardial $\mathrm{T} 2 *$ values $(<20 \mathrm{~ms})$ and impaired LV function. This was previously described in a study by Akcay et 
$\boldsymbol{a l}^{(\mathbf{2 2})}$ that showed that the LVEF level was lower in the high-risk group compared to the mild and moderate risk groups and there was a statistically significant difference among all groups. A study by $\boldsymbol{C h} \boldsymbol{u}$ et $\boldsymbol{a l l}^{(\mathbf{2 3})}$ also found a low myocardial $\mathrm{T} 2 *$ value was associated with more advanced left ventricular systolic and diastolic dysfunctions.

Another study by El Beshlawy et al. ${ }^{(24)}$ stated that the relationship between $\mathrm{T} 2 *$ and cardiac function is insignificant until a critical level is reached, and after which, rapid deterioration occurs. However, in the study of Daar $\boldsymbol{e t} \boldsymbol{a l}^{\left({ }^{(25)}\right.}$, there was no significant correlation between ejection fraction and cardiac $\mathrm{T} 2 *$.

No correlation with serum ferritin level was performed as many studies proved that $\mathrm{SF}$ is not a good predictor of cardiac iron overload in transfusion-dependent diseases. Ouederni et al. ${ }^{(26)}$ observed satisfactory serum ferritin SF level in patients having liver and cardiac iron overload, as was previously reported by several studies.

Chelation therapy is mandatory to remove tissue iron, prevent end organ damage and prolong survival. However, patient incompliance has been a major obstacle in achieving an optimal therapeutic result ${ }^{(24)}$. Low levels of liver iron or serum ferritin do not certainly signify reduced risk of iron-induced cardiomyopathy. This may occur because chelation therapy can eliminate iron more rapidly from the liver than from the heart ${ }^{(\mathbf{1 4})}$.

Therefore, measuring both cardiac and liver iron by MRI T2* became the primary outcome measures to reevaluate the iron chelation therapy being received and ensuring the optimal tailored dosage for each individual patient ${ }^{(18)}$. So it is promising to do MRI T2* for patient with thalassemia as a new and easy technique for early detection of iron overload and follow-up chelation therapy efficacy.

\section{Conclusion:}

MRI T2* provides a non-invasive, reproducible technique for measuring tissue iron load, sparing the patients from invasive biopsy and, also, provides a tool for adjustment and follow up of chelation therapy. Through the application of this technique, it should be possible to improve the management of tissue iron overload, and in particular aid the presymptomatic recognition of myocardial siderosis, allowing earlier chelation therapy intensification to reduce iron-induced cardiomyopathy and improve survival.

\section{REFERENCES:}

1. Baksi A and Pennell D (2014): Randomized controlled trials of iron chelators for the treatment of cardiac siderosis in thalassaemia major. Front Pharmacol, 5:217.

2. Borgna-Pignatti C, Galanello R (2009): Thalassemias and related disorders: quantitative disorders of hemoglobin synthesis. In: Wintrobe MM, Greer JP (eds) Wintrobe's clinical hematology, vol 2, 12th edn. Lippincott Williams \& Wilkins, Philadelphia,1336-1342.

3. Telfer P, Prestcott E, Holden S et al. (2000): Hepatic iron concentration combined with longterm monitoring of serum ferritin to predict complications of iron overload in thalassaemia major, $\mathrm{Br} \mathbf{J}$ Haematol; 110(4):971-977.

4. Berdoukas V, Nord A, Carson $\mathrm{S}$ et al. (2013): Tissue iron evaluation in chronically transfused children shows significant levels of iron loading at a very young age. Am J Hematol, 88: E283-E285.

5. Argyropoulou M, Astrakas I (2007): MRI evaluation of tissue iron burden in patients with beta-thalassaemia major. Pediatric Radiology, 37: 1191-200.

6. Wood J.C. (2007): Magnetic resonance imaging measurement of iron overload. Current Opinion in Hematology, 14: 18390.

7. Pepe A, Meloni A, Rossi G et al. (2013): Cardiac and hepatic iron and ejection fraction in thalassemia major: multicentre 
prospective comparison of combined deferiprone and deferoxamine therapy against deferiprone or deferoxamine monotherapy. J Cardiovasc Magn Reson, 15:1186-1532.

8. Modell B, Khan M, Darlison $\mathrm{M}$ et al. (2008): Improved survival of thalassaemia major in the UK and relation to $\mathrm{T}_{2}^{*}$ cardiovascular magnetic resonance. J Cardiovasc Magn Reson, 10:1186-1532.

9. Anderson L, Holden S, Davis B et al. (2001): Cardiovascular T2-star (T2*) magnetic resonance for the early diagnosis of myocardial iron overload. Euro Heart J., 22:2171-2179.

10. Barzin M, Kowsarian M, Akhlaghpoor S et al. (2012): Correlation of cardiac MRI T2* with echocardiography in thalassemia major. Eur Rev Med Pharmacol Sci, 16(2):254-260.

11. He T, Peter D, Gillian C et al. (2008): Myocardial T2* Measurements in Iron Overloaded Thalassemia: An in Vivo Study to Investigate the Optimal Methods of Quantification. Magn Reson Med., 60(5): 1082-1089.

12. $\mathrm{He} \mathrm{T}$ (2014): Cardiovascular magnetic resonance $\mathrm{T} 2 *$ for tissue iron assessment in the heart. Quantitative Imaging in Medicine and Surgery, 4(5):407-442.

13. Tanner M, Galanello R, Dessi C et al. (2006): Myocardial iron loading in patients with thalassemia major on deferoxamine chelation. J Cardiovasc Magn Reson., 8:543-7.

14. Chaosuwannakit N, Makarawate P (2019): The value of magnetic resonance imaging in evaluation of myocardial and liver iron overload in a thalassaemia endemic population: a report from Northeastern Thailand. Pol J Radiol., 84: e262-e268.

15. Voskaridou E, Douskou M, Terpos E et al. (2004): Magnetic resonance imaging in the evaluation of iron overload in patients with beta thalassemia and sickle cell disease. $\mathrm{Br}$ J Haematol., 126: 736-742.

16. Kirk P, He T, Anderson L et al. (2010): International reproductibility of single breath hold T2* MR for cardiac and liver iron assessment among five thalassemia centers. J Magn Reson Imaging, 32:315319.
17. Quatre A, Jacquierb A, Petit P et al. (2014): MRI monitoring of myocardial iron overload Use of cardiac MRI combined with hepatic MRI in a cohort of multitransfused patients with thalassaemia. Diagnostic and Interventional Imaging, 95: 1065-1069.

18. Wahidiyat P, Liauw F, Sekarsari D et al. (2017): Evaluation of cardiac and hepatic iron overload in thalassemia major patients with $\mathrm{T} 2 *$ magnetic resonance imaging. Hematology, 22(8):501-507.

19. Merchant R, Joshi A, Ahmed J et al. (2011): Evaluation of cardiac iron load by cardiac magnetic resonance in thalassemia. Indian Pediatric, 48(9):697-701.

20. Deborah C, Geukes-Foppen M, Barry K et al. (2008): Practical implications of liver and heart iron load assessment by T2*-MRI in children and adults with transfusiondependent anemias. Am J Hematol., 83(10):781-783.

21. Farhangi $\mathrm{H}$, Badiei z, Moghaddam $\mathrm{H}$ et al. (2016): Assessment of heart and liver iron overload in thalassemia major patients using $\mathrm{T} 2 *$ magnetic resonance imaging. Indian J Hematol Blood Transfus., 33(2): 228-234.

22. Akcay A, Salcioglu Z, Oztarhan K et al. (2014): Cardiac T2* MRI assessment in patients with thalassaemia majorand its effect on the preference of chelation therapy. Int J Hematol., 99:706-713.

23. Chu W, Au W, and Lam W (2012): MRI of Cardiac Iron Overload. Journal of Magnetic Resonance Imaging, 36:1052-1059.

24. El Beshlawy A, El Tagui M, Hamdy M et al. (2014): Low prevalence of cardiac siderosis in heavily iron loaded Egyptian thalassemia major patients. Annals of Hematology, 93, 375-379.

25. Daar S, Pathare R, Jain V et al. (2009): Pennell $\mathrm{T} 2 *$ cardiovascular magnetic resonance in the management of thalassemia patients in oman. Haematol J., 94 (1):140-1.

26. Ouederni M, Ben Khaled M, Mellouli F et al. (2016): Myocardial and liver iron overload, assessed using $\mathrm{T} 2 *$ magnetic resonance imaging with an excel spreadsheet for post processing in Tunisian thalassemia major patients. Ann Hematol., 16: $2841-5$ 
دور التصوير بواسطة الرنين المغناطيسى للقلب والأوعية الدموية في تقييم الحديد الزائد فى عضلة القلب

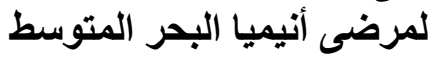

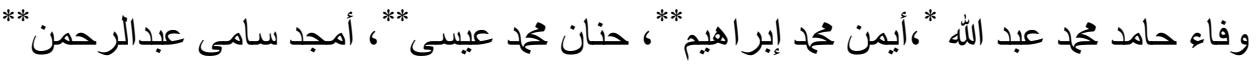

*قنم الأشعة التشخيصية - مستشفى منشية البكرى - وزارة الصحة

| - قسم الأشعة التثخيصية ـ كلية الطب - جامعة عين شمس

مقدمه: أنثتت تقنية الرنين المغناطيسى على عضلة القلب (cMRI T2) أنها الطريقة الأكثر فاعلية فى قياس نسبة

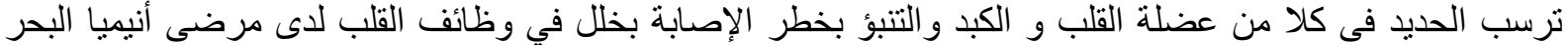
المتوسط من خلال تقييم وظائف القلب في نفس الوقت. علاوة على ذلك، فقد ثبت أنه أداة مفيدة لمر اقبة وتقييم فعالية العلاج لاى هؤلاء المرضى مما يسمح بتعديله

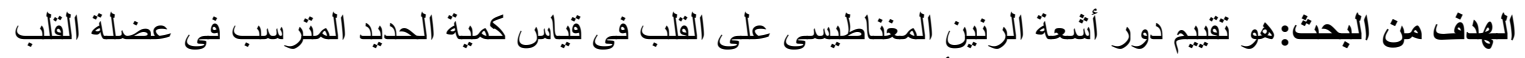

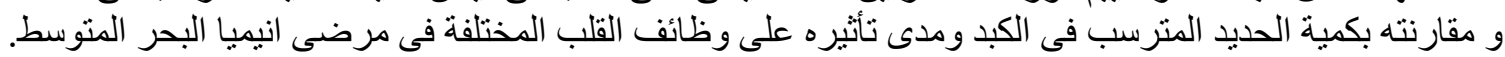

طريقة البحث: يتضمن البحث بـ مريض أنيمبا البحر المتوسط وجميع المرضى بتلفو ا نقل دم بانتظام و قد نم استخدام

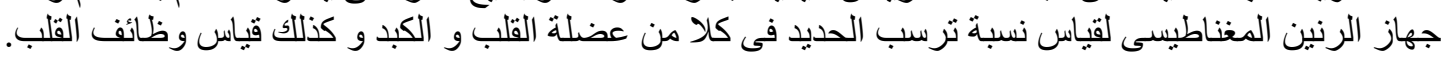

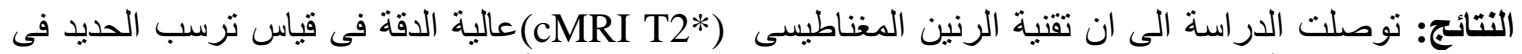

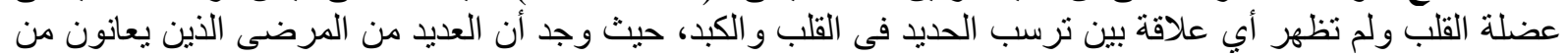

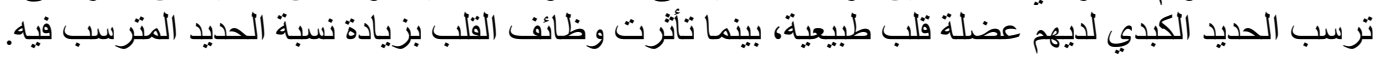

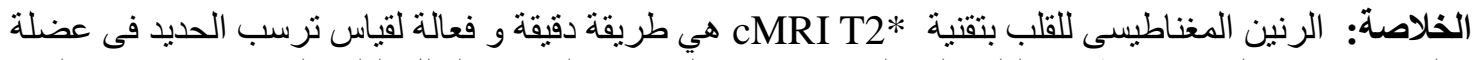

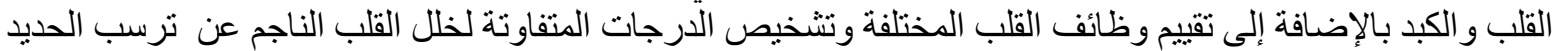
مبكر ا وأيضا تعديل و متابعة فاعلية الخطة العلاجية. 